American Journal of Economics and Business Administration 3 (1): 150-156, 2011

ISSN 1945-5488

(C) 2010 Science Publications

\title{
Assistive Courseware for the Visually Impaired based on Theory of Multiple Intelligence and SECI Model
}

\author{
${ }^{1}$ Nurulnadwan Aziz, ${ }^{1}$ Nur Hazwani Mohamad Roseli, \\ ${ }^{1}$ Erratul Shela Eshak and ${ }^{2}$ Ariffin Abdul Mutalib \\ ${ }^{1}$ Faculty of Office Management and Technology, \\ University of Technology MARA Terengganu, Dungun Campus, \\ 23000 UiTM Dungun, Terengganu, Malaysia \\ ${ }^{2}$ Applied Science, College of Arts and Sciences, \\ University Utara Malaysia, \\ 06010 UUM Sintok, Kedah, Malaysia
}

\begin{abstract}
Problem statement: Courseware is one of the educational aids in teaching and learning process. Nowadays, courseware together with multimedia elements is utilized to ease learners in grasping knowledge. However, the courseware for Visually-Impaired (VI) is yet to be developed. Approach: This study discusses the development of Assistive Courseware (AC) for visually impaired learners based on Theory of Multiple Intelligence (MI) and also adapt knowledge spiral model. It explains how the AC delivers knowledge to VI learners. The phases, design and development methods involved in the research are outlined. Results: Results showed that the AC is fully equipped with the eight types of MI theory and the use of SECI model in transferring knowledge between AC and VI learners has been proven. Conclusion: The AC has been proposed for the VI learners and observed on their reactions. Overall, the VI learners were vary positive upon the AC and was excited to learn with the AC. Next step of the study is not only to report on the findings from observation, but also to experiment the prototype with VI learners in terms of cognitive implications using empirical data.
\end{abstract}

Key words: Multiples intelligence theory, SECI model, Assistive Courseware (AC), VisuallyImpaired (VI), Knowledge Management (KM), VI learners, verbal-linguistic intelligence

\section{INTRODUCTION}

Today's world has been representing hectic circumstances of managing intellectual assets into a corporate memory. This would end up by containing value and used by organization as its competitive advantage. All kind of information is accessible these days (Venkatesh and Thangaraj, 2008). Through the process of Knowledge Management (KM), intellectual and knowledge based assets can be generated (Singer and Hurley, 2005) in which the intellectual assets will be derived through collective perspective, insights, ideas, best practices and lessons learnt.

Meanwhile, knowledge is the key factor for driving growth, creating new value and providing the basis to remain competitive (Mihalca et al., 2008; Stevens et al., 2010). Yordanova (2007) adds that KM is a method to simplify and improve the process of sharing, distributing, creating, capturing and understanding knowledge.
In a nutshell, $\mathrm{KM}$ is a discipline originating from management studies, but always going hand in hand with information technologies (Mihalca et al., 2008). In addition, technology-based knowledge is driven by choice and implementation of suitable tools of interactions (Pedroni, 2007). KM technology can be seen it as technological attributes of a tool for online interaction to support KM process.

The SECI Model above illustrated about the process of knowledge creation. This model met with broad acceptance due to its intuitive logic and clear delineation of knowledge types between tacit and explicit knowledge (Rice and Rice, 2005). According to Hafeez and Alghataz (2007); Rice and Rice (2005) there are four modes of knowledge transfer, namely socialization, externalization, combination and internalization as depicted in Fig. 1 and known as SECI:

Corresponding Author: Nurulnadwan Aziz, Faculty of Office Management and Technology, University Technology MARA Terengganu, Dungun Campus (UiTM), 23000 UiTM Dungun, Terengganu, Malaysia 
Am. J. of Economics and Business Administration 3 (1): 150-156, 2011

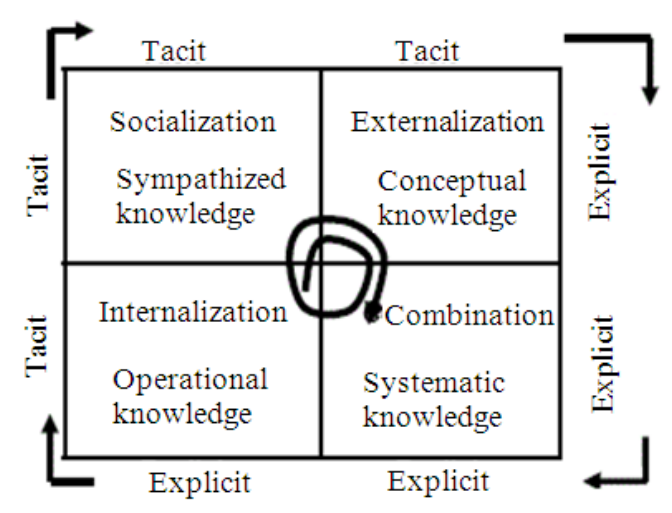

Fig. 1: SECI Diagram representing four modes of Knowledge transfer

Socialization (tacit to tacit): Where knowledge being transferred in a tacit form individually. Process involves by acquiring knowledge through share feelings, emotions, experiences and perceptual models.

Externalization (tacit to explicit): This field included meaningful reflections whereby tacit knowledge is transferred and documented to explicit form. It occurs articulations of transferring knowledge through two methods are dialogue and metaphor creation.

Combination (explicit to explicit): Systemic collaboration in a virtual space, where information technology facilitates the recombination of existing explicit knowledge to form new explicit knowledge.

Internalization (explicit to tacit): The final mode of knowledge spiral represent the process of "learning by doing" and through a verbalization and documentation of experiences whereby explicit knowledge is converted into tacit knowledge.

On the other hand, individual differences determine different styles of learning. It is said that each individual differs in traits such as skills, aptitudes and preferences for processing information and applying in real world situations (Jonassen and Grabowski, 1993; Bushro and Halimah, 2006) and it is called personal knowledge. In relation, MI is one of the prominent theories regarding individual differences. It allows process of learning and understanding in dynamic and logical ways basing to the individual performance capability. The theory serves as one of the most effective curricular and instructional frameworks for classrooms teachers to use in designing their lesson plan (Bushro and Halimah, 2006).
According to Gardner as cited in (Bushro and Halimah, 2006)), he said that "intelligence" is the ability to solve problems, or to create products, that are valued within one or more cultural setting. (Gardner, 1993) and (Bushro and Halimah, 2006) discussed that each individuals has eight types of intelligences, in which each individual may have good skills at different types. The intelligences are as follow:

Verbal-linguistic intelligence: This involves sensitivity to spoken and written language, the ability to learn languages and the capacity to use languages to accomplish certain goals.

Mathematical-logical intelligence: This involves the capacity to analyze problems logically, carry out mathematical operations and investigate issues scientifically.

Visual-spatial intelligence: Features the potential to recognize and manipulate patterns of wide space as well as patterns of more confined areas.

Intrapersonal intelligence: Involves the capacities to understand oneself, to have an effective working of oneself including one's own desire, fears and capacities and to use such information effectively in regulating one's own life.

Bodily-kinesthetic intelligence: Entails the potential of using one's whole body or parts of the body to solve problems or fashion products.

Interpersonal: Denotes a person's capacity to understand the intentions, motivations and desires of other people and consequently to study effectively with others.

Naturalist intelligence: Demonstrate expertise in the recognition and classification of the numerous species the flora and fauna of his or her environment.

Musical-rhythmic intelligence: In the intelligence, individuals entail skills in performance, composition and appreciation of musical patterns.

The MI with its eight types of intelligences has been used as the basis for a number of multimedia application developments for teaching and learning. This can be seen in works by (Ariffin and Norshuhada, 2009; Faridah-Hanim et al., 2008). Multimedia features including text, graphics, animation, audio and video can cater for all types of intelligences (Chapman et al., 2007). 
Inline with the above-discussed theory, multimedia has been used tremendously in Malaysian school after the introduction of the Smart School project. One of the most popular multimedia applications is courseware (Ariffin and Norshuhada, 2008). It is interactive and is one of the multimedia applications that could enhance the student's performance in their learning process (Norhayati, 1999). It also assists teachers in teaching. However (Nurulnadwan et al., 2009) found that the existing coursewares are not developed for the Visually Impaired (VI) people as an Assistive Courseware (AC).

AC can be defined as a courseware that is designed for VI people to learn and enjoy lesson like normal people, applying special instructional approach and provides special elements for VI people. This differentiates them from other coursewares that are available in the market. In our previous findings we discussed on how VI people can make full use of the AC (Nurulnadwan et al., 2009). This study aims to discuss the prototype of AC which is designed incorporating the MI theory. The design and development of the AC for VI people is discussed next.

\section{MATERIALS AND METHODS}

Iterative Triangulation Methodology (Lewis, 1998) was used as a foundation of this research while the development is based on the IntView methodology (Grutzner et al., 2002). This section explains the phases involved in the research and describes the design and development of the AC.

Phases: Four phases involved in the AC development. The phases are Phase 1: Specification Identification, Phase 2: Assistive Courseware for Visual Impaired Development, Phase 3: Testing and Evaluation and Phase 4: Revise and Enhance Prototype. Figure 2 outlines the summary of activities employed in the research. This study is only focused on the activities in Phase 4. The eight types of MI Theory were adopted in the AC. Meanwhile, SECI Model is used as a basis of transferring knowledge between AC and VI learners.

Design and development: Designing and developing the AC includes outlining the storyboard. This part is crucial because it will determine the successful of the AC. The storyboard has been designed in detail to make sure the prototype of AC meets the eight types of intelligence in MI theory. Figure 3 illustrates the storyboard. The AC consists of four main modules: Fig. 3a: Module 1-“Mari Menyanyi”; Fig. 3b: Module 2-“Mari Mengenal Haiwan”, Fig. 3c:

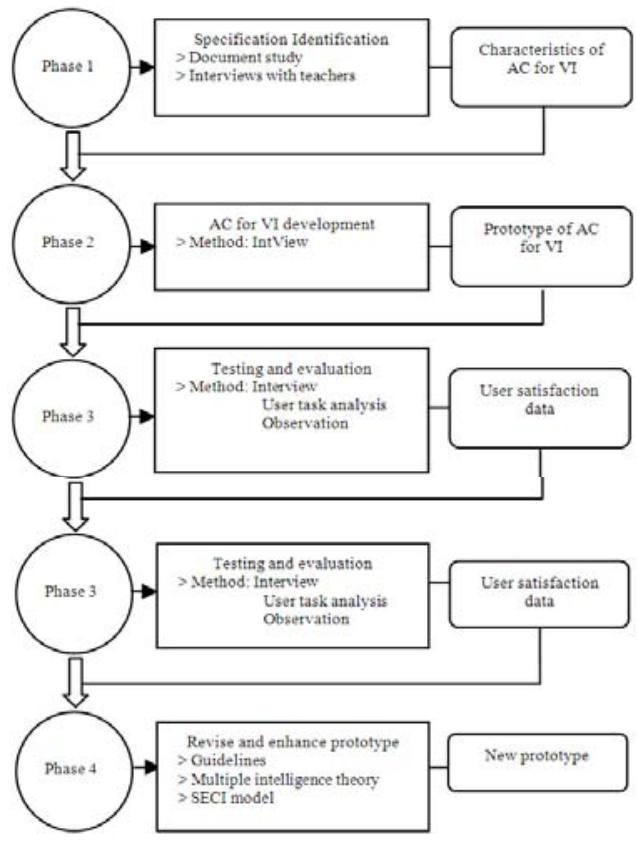

Fig. 2: Summary of activities

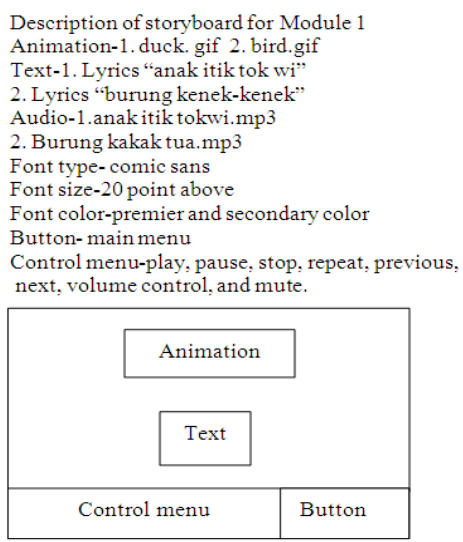

(a)

Description of storyboard for Module 2 Animation-1.cow.gif, 2.sheep.gif, 3.duck.gif, 4.cat.gif, 5.rooster.gif, 6. bird. gif, 7. tiger.gif, 8.eleplant.gif, 9.bear.gif

Text-description of animals

Audio-1.cow.mp3, 2. sheep.mp3,3.duck.mp3,

4.cat.mp3, 5.rooster.mp3, 6.bird.mp3.

7.tiger.mp3, 8.eleplant.mp3, 9.bear.mp3

Font type-comic sans

Font size-20 point above

Font color-premier and secondary colo

Button- main menu

Control menu-play, pause, stop, repeat,

previous,

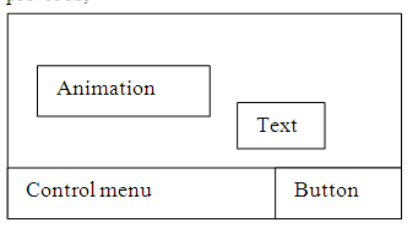

(b) 


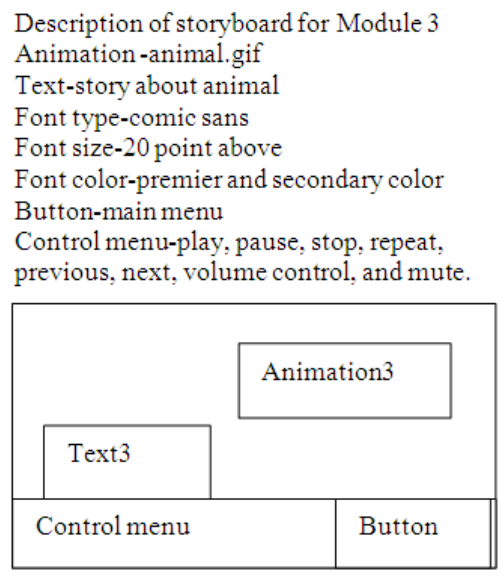

(c)

Description of storyboard for Module 4 Animation-1. tiger.gif 2. elephant.gif Text-1. Exercise 1-multiple choice, 2. Exercise 2-Fill in the blank

Font type-comic sans Font size-20 point above

Font color-premier and secondary color Button-main menu

Control menu-play, pause, stop, repeat, previous, next, volume control, and mute.

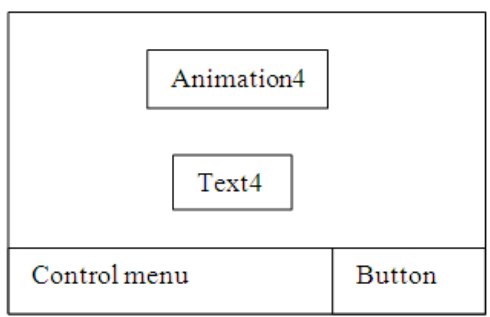

(d)

Fig. 3: Storyboard. (a) Storyboard of Module 1; (b) Storyboard of Module 2; (c) Storyboard of Module 3; Storyboard of Module 4

Module 3-“Tahukah Anda” and Fig. 3d: Module 4"Mari Menguji Minda". Each module is supplied with control functions so that the users can play, pause, stop, go to the next and previous scene, mute the audio and control the volume on their own. Furthermore, all audio are in .mp3 format and all graphics and animations are in .gif format.

Having designed the storyboard, the AC was developed. Adobe Flash was used to develop the AC. The next section discusses on how the principles of MI and SECI model is incorporated in the AC.

\section{RESULT}

Results showed that the AC is fully equipped with the eight types of MI theory and the use of SECI model in transferring knowledge between AC and VI learners has been proven.

\section{DISCUSSION}

This section highlights the MI theory that has been implemented in the AC. Figures 4-6 illustrate the samples of snapshots labeled with types of intelligence. MI theory has been used as guidance to identify, characterize and understand user behavior (Ramadhan, et al., 2005). Modules and activities that include in the design of AC content that meet the eight types of intelligence are discussed as follow:

Verbal-linguistic intelligence: Module 2 and Module 3 provided in the AC enables the VI learners to learn several types of animals in different environments. Module 2 focuses on learning wild animals, domestic animals and pets. The animals are segregate into category to help learners in term of understanding and differentiating the animals. This knowledge involves the verbal-linguistic intelligence. The knowledge comes through the spelling and description for each animal displayed on a screen. Narrations are supplied in each scene parallel with the lines of words and character by character. These elements can help VI learners in understanding the knowledge better. Enabling users in this case VI learners to listen to a computer application (AC) will greatly enhance the ability for them to access $\mathrm{AC}$ at any time and any place (Manoharan, et al., 2009). Mother tongue language was decided as the most appropriate medium when the previous research shows that VI learners facing difficulties in understanding English (Yi-Chun and Pi-Ching, 2009; Nurulnadwan et al., 2009).

Logical-mathematical intelligence: This initial version of AC only focuses on logical characteristic. Module 4 contains IQ Test to examine students' knowledge level after learning with the AC. This module is divided into two parts. Part A offers Multiple Choice Question. Students have to match the sound with correct animal. Part B requires students to fill in the blanks. Based on the descriptions along with the audio, students need to type the correct answer. Both parts require students to think logically based on their understanding throughout the learning process.

Visual-spatial intelligence: Students learn best when they are seeing. This type of intelligence is focused on the VI learners who have low vision and color blindness problems. One of the main problems for them is to perfectly recognize the main object from its 
background (Nordin and Ali, 2009,). Due to that, largescale pictures and simple animated elements are provided in the AC. VI learners grasp the knowledge through object, shapes and patterns designed in the AC. Other than that the font face, font size and font color are also within considerations. The most preferred font face is sans serif types, readable font size is at least 20pointand font color must contrast with the background color (Yi-Chun and Pi-Ching, 2009).

Intrapersonal intelligence: The whole parts contained in the AC represent the intrapersonal intelligence. Module 1 offers VI learners to learn through songs. Hearing and singing songs at the beginning of the AC is a strategy to attract VI learners with the learning process. Modules 2 and 3 develop the knowledge of VI learners. Module 4 aids them in testing their knowledge. The activities throughout the learning process indirectly affect the VI learners. Knowledge and information provided by the AC enables the VI learners to face the real world setting.

Bodily-kinesthetic intelligence: After experiencing the learning process, students can test their knowledge by answering quizzes offered by Module 4. VI learners need to insert the answer by using keyboard. This process represents the bodily-kinesthetic intelligence. This fosters the concept of active learning (Bonwell and Eison, 1991), in which the VI learners' engagement within the learning environment is required. The ability of inserting multimedia components such as text, graphic and sound can give the AC more advantages for VI learners to interact with the courseware (Rjoub, et al., 2009). It is also a part of media interaction behavior in which how the VI learners can organizes their mind to answer the question in Module 4 (Yampolskiy, 2008).

Interpersonal intelligence: The AC is proposed to be utilized in either classroom or at home. VI students usually learn and study together. They communicate with each other and with their instructor. This could enhance their interpersonal skill. This also promotes the VI learners to learn on their own pace (Mateik, 2000) on their own time, at their preferred place, in their own convenience.

Naturalist intelligence: Numerous animal pictures together with flora and fauna environment are the main key elements in the AC. Other than that, with the help of animal sounds, VI learners can feel and imagine the real nature environment.
Musical-rhythmic intelligence: Music is one of the important medium in teaching and learning process (YiChun and Pi-Ching, 2009). Module 1 enables the VI students to learn various types of animals by listening to the songs provided. At the same time, they enjoy the learning process. Module 4 is equipped with the sound effect. In this module students are needed to enter a correct answer for each of the question given. Different sound effects are used to distinguish between correct and wrong answer. Other than that, all modules in this courseware are supplied with the audio-narrations.

Learning is an essential ingredient for developing individual and corporate competences in the knowledge society (Hafeez and Alghataz, 2007). Using the specific tools for knowledge management namely spiral model, the researchers would argue these are useful tools to explain how the knowledge is transferred in the context of AC as the medium. SECI diagram will be used to discuss how knowledge is shared and generated and learning take place using $\mathrm{AC}$ in delivering the knowledge to VI learners. The following part discusses how the four modes of knowledge conversation using $\mathrm{AC}$ as the medium in transferring knowledge:

Socialization (from tacit to tacit): Module 1 provided in the AC enables the VI learners to learn many types of animals via songs. At the same time Module 1 also encourage them to sing together with their friends and instructor. According to the SECI model, tacit to tacit which is socialization will represent individuals. In Module 1 they had face to face communication via singing together. Transferring knowledge in the form of tacit to tacit occurs here when the VI learners grasps the knowledge through the others singing. Here, they can share feelings, emotions and experiences.

Externalization (from tacit to explicit): $A C$ is the medium of transferring knowledge from tacit to explicit. This can be proved via Module 1, Module 2and Module 3. As discussed above Module 1 offers VI learners singing the animals songs. Before using the AC VI learners might have heard about the animals’ songs anywhere through informal ways. Transferring knowledge from tacit to explicit happen when the VI learners learn the songs provided by the AC. Module 2 and Module 3 offers VI learners to learn the fact about animal. Module 2 provides the description about the animals and Module 3 provides the fact about the animal. Before using the AC VI learners might have learned about the animals through the informal ways for example when they visit to the zoo. The fact about the animals they will get through the AC. 


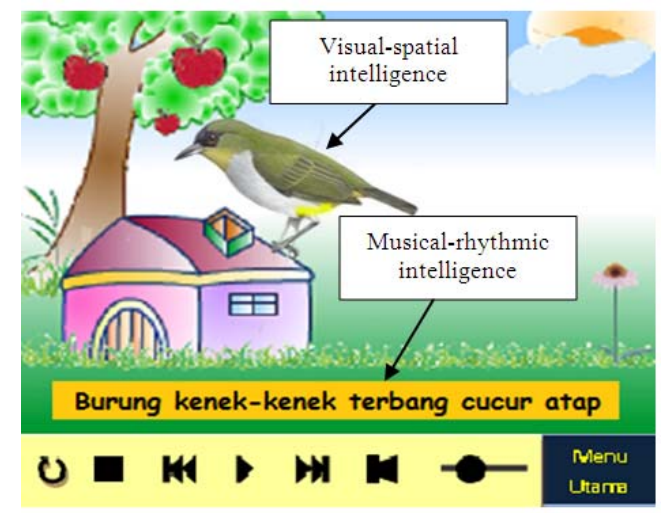

Fig. 4: Snapshot of module 1

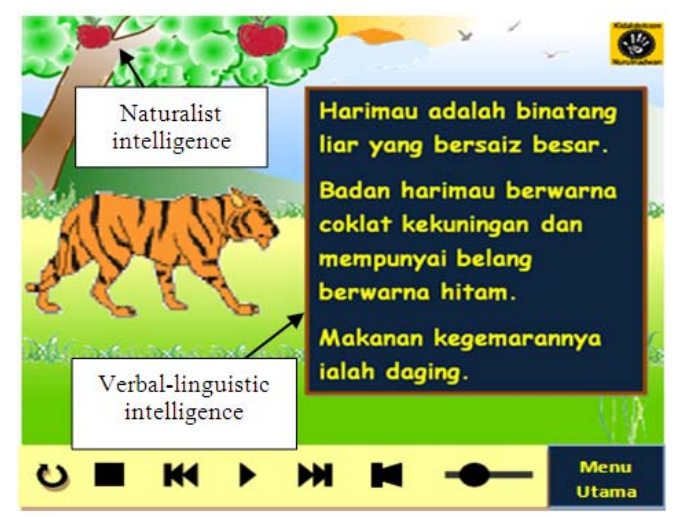

Fig. 5: Snapshot of module 2

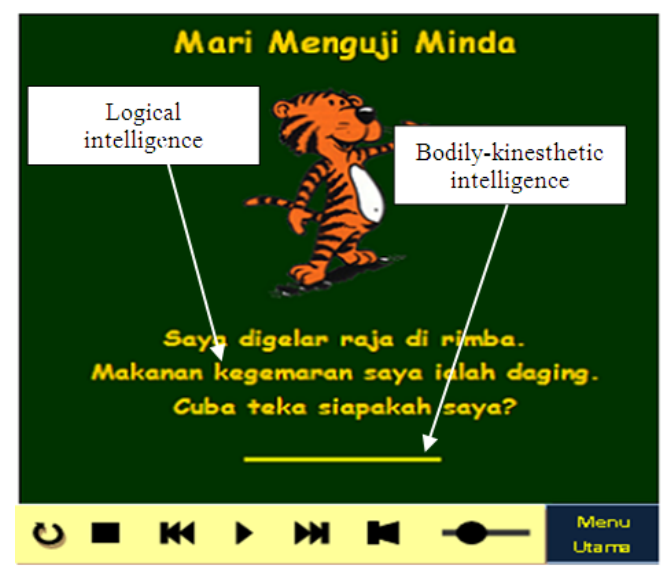

Fig. 6: Snapshot of module 4

Combination (from explicit to explicit): As described on the Fig. 1, combination is a process of transmission from explicit to explicit type of knowledge. It can be successfully done by facilitating of information technology usage of existing explicit knowledge to the new explicit knowledge. This knowledge creation could determine by providing modules based on the guidelines (Nurulnadwan et al., 2009) and MI theory to be produced with an AC. All the modules provided by the AC were developed based on the guidelines (Nurulnadwan et al., 2009) and MI theory. Knowledge transfer applied here in the form of explicit to explicit where the guidelines and MI theory is explicit knowledge and the AC is explicit knowledge.

Internalization (from explicit to tacit): Internalization is about learning by doing. Through all modules offered by the AC VI learners should transfer and share the knowledge with others outside the class.

\section{CONCLUSION}

The main discussion of this study is on the incorporation of the eight types of intelligence in MI theory in the AC for VI learners. The use of four modes in SECI model to transfer knowledge between AC and VI learners has been proven. The whole part of the AC represents the eight types of intelligence in MI theory. The AC has been proposed for the VI learners and observed on their reactions. Overall, the VI learners were vary positive upon the AC and was excited to learn with the AC. This study has no intention to discuss about the findings from the observation.

Next step of the study is not only to report on the findings of the observation, but also to experiment the prototype with VI learners in terms of cognitive implications using empirical data.

\section{REFERENCES}

Ariffin, A.M. and Norshuhada, S. 2009. Conceptual design model of Reality Learning Media (RLM). Proceedings of IADIS International Conference eSociety 2009, Feb. 25-28, IADIS ,Barcelona, Spain, pp: 1-5.

Bonwell, C.C. and J.A. Eison, 1991. Active Learning: Creating Excitement in the Classroom. 1st Edn., Jossey-Bass, ISBN: 1878380087, pp:128.

Bushro, B A. and H.B.Zaman 2006. Framework for adaptive multimedia mathematics courseware. Proceedings of 2nd IMT-GT Regional Conference on Mathematics, Statistics and Applications. June 13-15, University sains malasiya, Penang, pp: 1-7.

Chapman, N. and N.P. Chapman and J. Chapman, 2007. Digital Media Tools. 3rd End., John Wiley and Sons, Ltd. England, ISBN: 0470012277, pp: 520. 
Faridah-Hanim, Y. and Halimah, B.Z.H. Hj, 2008. Development of interactive multimedia courseware using problem based learning for mathematics form 4 (PBL MathS-Set). Proceedings of International Symposium on Information Technology. Aug. 26-28 2. IEEE Xplore Press, Kuala Lumpur, Malaysia, pp: 1-6. DOI: 10.1109/ITSIM.2008.4631737

Gardner, H., 1993. Multiple Intelligences: The Theory in Practice. 30 Edn., Basic Books, New York, ISBN: 046501822X, pp: 304.

Grutzner, I., N. Angkasaputra and D. Pfahl, 2002. A systematic approach to produce small courseware modules for combined learning and knowledge management environments. Proceedings of the 14th International Conference on Software Engineering and Knowledge Engineering, (ICSEKE'02), ACM New York, USA., pp: 533-539. DOI: $10.1145 / 568760.568855$

Hafeez K. and Alghataz, F. 2007. Knowledge management in a virtual community of practice using discourse analysis. Elec. J. Know. Manage., 5: 29-42.

Jonassen, D.H. and Grabowski, B.L. 1993. Handbook of Individual Difference, Learning and Instruction. 1st Edn., Routledge, ISBN: 0805814132, pp: 512.

Lewis, M.W., 1998. Iterative triangulation: A theory development process using existing case studies. J. Operat. Manage., 16: 455-469. DOI: 10.1016/S0272-6963(98)00024-2

Manoharan, R., K. Vivekanandan and V. Sundaram, 2009. A software agent for speech abiding systems. J. Comput. Sci., 5: 90-96. DOI: 10.3844/jcssp.2009.90.96

Mateik, D. 2000. Self-paced student tutorial in the WebCT environment. Proceeding of the 28th Annual ACM SIGUCCS Conference on user service, Building future, (ACUSBF'00), ACM Press, New York, pp: 351-352. DOI: 10.1145/354908.354991

Mihalca. R., A. Uta, A. Andreescu and I. Intorsureanu, 2008. Knowledge management in e-learning system. Revista Inform. Econo., 2: 60-65.

Mutalib, A. and S. Norshuhada, 2008. Usable but not entertaining e-learning material. Proceedings of World Conference on E-Learning in Corporate, Government, Healthcare and Higher Education, Nov. 17, Las Vegas, Nevada, USA., pp: 11-19.

Nordin, M. J. and Ali, A.M. 2009. Indoor navigation and localization for visually impaired people using weighted topological map. J. Comput. Sci., 5: 883-889. DOI: $10.3844 /$ jcssp.2009.883.889
Norhayati, A.M., 2000. Perisian Pengarangan. 1st Edn., Prentice Hall, Sdn Bhd, ISBN: 9839236369, pp: 231.

Norshuhada, S., M. Landoni, F. Gibb and H. Shahizan, 2003. E-books technology and its potential applications in distance education. J. Digital Inform., http://www.citeulike.org/group/13454/article/7136 144

Nurulnadwan, A., M.R. Nur-Hazwani and A.M. Ariffin, 2009. Assistive courseware for visually-impaired. Lect. Notes Comput. Sci., 5857: 905-915. DOI: 10.1007/978-3-642-05036-7_86

Pedroni, M. 2007. E-learning and knowledge management: Context structuration. Proceedings of the Informing Science and IT Education Joint Conference, (ISTEJC' 07), CARID University of Ferrara, Italy, pp: 1-8.

Ramadhan, H., M. Hatem, Z.A. Khanjri and S. Kutti, 2005. A classification of techniques for web usage analysis. J. Comput. Sci., 1: 413-418. DOI: 10.3844/jcssp.2005.413.418

Rice, J.L. and B.S. Rice, 2005. The applicability of the seci model to multi-organizational endeavors: An interactive review. Int. J. Org. Behav., 9: 671-682.

Rjoub, A., Y. Eyadat, A. Ghazawi, B. Tall and N. Sharou et al., 2009. A multi-form multiple choice editor exam tool based on HTML website and artificial intelligence techniques. J. Comput. Sci., 5: 405-412. DOI: $10.3844 /$ jcssp.2009.405.412

Singer. P.M. and J.E. Hurley, 2005. The importance of knowledge management today. ALA-APA., 2: 1-3.

Stevens, R.H., J. Millage and S. Clark, 2010. Waves of knowledge management: The flow between explicit and tacit knowledge. Am. J. Econ. Bus. $\begin{array}{lll}\text { Admin., } & \text { 2: } & 129-135 .\end{array}$ 10.3844/ajebasp.2010.129.135

Venkatesh, E.T and P. Thangaraj, 2008. Self-organizing map and multi-layer perceptron neural network based data mining to envisage agriculture cultivation. J. Comput. Sci., 4: 494-502. DOI: 10.3844/jcssp.2008.494.502

Yampolskiy, R.V., 2008. Behavioral modeling: an overview . Am. J. Applied Sci., 5: 496-503. DOI: 10.3844/ajassp.2008.496.503

Yi-Chun, C. and C. Pi-Ching, 2009. The effect of English Popular Songs on Learning Motivation and Learning Performance. WHAMPOA-An Interdisciplinary J., 56: 13-28.

Yordanova, K., 2007. Integration of Knowledge management and e-learning: Common features. Proceeding of the International Conference on Computer Systems and Technologies, (CST'07), ACM Press, New York, pp: 25-31. DOI: 10.1145/1330598.1330697 